\title{
Seeing with light and landscape: A walk around Stanton Moor
}

This paper focuses on the much-neglected contribution of light to the conceptualization of landscape. I discuss how light circulates through our visual system and around the spaces we see, refuting notions that we can be detached from the landscapes that we view and characterize. Though we see with the vital light and the landscape, I emphasize that our experiences are invariably entangled with prevalent cultural values, meanings and representations. By drawing upon the experience of walking around an area of raised moorland in the Peak District, I suggest that the experience of particular landscapes can be distinguished by the changing light that radiates upon them and to which we continuously become attuned. By composing an autoethnographic account that highlights key moments when its effects seemed particularly acute, I exemplify the distinctive ways in which the shifting light interacts with elements within this particular landscape

KEYWORDS: Light, landscape, vitalism, perception, sensation

\section{Considering Light and Landscape}

Light pervades the world during the daylit hours, and the perception of space with this light is an integral dimension of human existence. Sighted humans and other animals perceive, interpret and mark time in accordance with the changing qualities of luminosity or murkiness that pervade the visible world. Light is the medium with which they continuously adapt, adjusting to qualities of brilliance, colour, intensity, radiance, shade and gloom. Despite this, social science investigation of daylight, darkness and illumination is meagre, a lacuna that extends to explorations and conceptions of landscape. This is startling if we consider how sunlight and shade condition the appearance of the landscape, informing the meanings attributed to its luminous and shadowy qualities. For light produces widely differing effects on diverse landscapes, interacting with their material qualities in distinctive ways. Geographical divergences in the distribution of sunlight over diurnal cycles and seasons, and during particular weather conditions, are key factors in shaping the apprehension of landscape, and these are supplemented by the intensity of the sun's rays and the qualities of the surfaces upon which light reflects, deflects and is absorbed. The material features and surfaces of landscape mediate light: it is 
diffused by translucent clouds, reflected by water and absorbed by the pigment cells of plants that produce photosynthesis.

Light is a form of radiant energy that is not perceived in itself but rather through the visual perception of the varying colours and intensities it produces as it shines on landscape. Light enters our eyes and enables us to discern selective parts of the electro-magnetic spectrum. The entanglement of light and perception thus foregrounds the circulation between that which we commonly assign as external and internal. Vision is facilitated when the eye's convex lens focuses light to produce an inverted image of a scene on the retina. The iris expands and contracts in controlling the amount of light admitted. The image is sent via the optic nerve to the brain, which processes this information, crucially controlling selection of the infinite elements in the field of view. The light-sensitive receptors on the retina are of two kinds, cones and rods, that respond to different wavelengths of light and consequently produce two different modalities of vision. The cones function when the eye adapts to normal levels of (day)light, allowing the experience of a colour spectrum, whereas the rods operate when there are low levels of light and lack the ability to distinguish colour.

These perceptual capacities and the manifold effects of light shape everyday experience, influencing the epistemologies, affects and sensations that inform our familiarity with quotidian landscapes. Though these habitual experiences are largely unreflexive, they anchor us in place, conditioning how we feel, practice and make sense of the places and landscapes in which we live and move through. In this paper, I redress the persistent lack of any substantive theoretical consideration about the relationships between humans, light and landscape.

Post-structuralist studies of landscape focus on symbolic qualities (for instance, cultural Marxists Cosgrove, 1984 and Mitchell, 1994), reading the landscape as a text inscribed with cultural meanings and historical practices that resonate with power. Yet they rarely consider the symbolic role of light even though painters have long deployed the effects of light in landscape to convey a multitude of metaphorical and allegorical meanings. Besides disregarding how qualities of light are interpreted and evaluated, and in investigating how the landscape is read as a cultural artefact, they neglect how it is sensed or affectively experienced. Strikingly, even in those works in which geographers focus on vision, light gets little mention (Daniels, 1993). 
In a significant advance, recent studies veer away from solely considering landscape as a textual artefact, adopting non-representational and phenomenological perspectives (Wylie, 2007), yet they also only cursorily refer to light's centrality to embodied experience.

This particularly noticeable in the influential work of Wylie, with his apposite insistence on the lack of separation between the internal and external. Here, landscape constitutes neither object nor subject but blends distinctions between the looked upon and the onlooker (2006). Immersed in the currents and energies of a world-in-formation, the cultural conventions that construe us as creatures separated from the landscape are, Wylie argues, demonstrably false. For both human bodies and landscapes continuously emerge, partly through their unceasing interaction with each other (Morris, 2011). This lack of separation thus pertinently infers that landscape constitutes 'the materialities and sensibilities with which we see' (Rose and Wylie, 2006: 478). Yet in this important discussion, the agency of light is curiously absent.

However, it is light that enables vision as it circulates between the interior and exterior, blurring the division between the viewing subject and the landscape that is perceived. Thus rather than conceiving landscape through an outmoded 'static pictorialism' construed by the conventions of touristic gazing and aesthetic appreciation that instruct us how to look upon, assess, understand and characterise landscape, we should reflect upon how we see with the light that falls upon the landscape and circulates through our visual system (Saito 2008). In considering this internal-external dynamic, it is apparent that a vitality inheres in both our perception of the world with light and in the play of light across space. This dynamic radiance reveals one aspect of the ways in which landscapes are never pre-formed but are 'always in process... always in movement, always in making', vitally immanent and emergent (Bender 2001: 3; Benedicktsen and Lund, 2010). Landscape is alive with energies, eternally fluid, its rocks, earth, vegetation and climate continually changing as elements are entangled and folded together in a continual making. Rather than evoking static notions that suggest intrinsic being and permanence, landscapes seethe with multiple rhythms and temporalities as elements within it incessantly emerge, decay, die and transform (Edensor, 2011). 
Despite this emergent vitality, we persistently make sense of landscapes by identifying the look of the land, its shape and form, and reifying particular scenic prospects through popular cultural representations, instead of focusing on 'substance', textures sounds, smells and tactility, qualities that herald landscape's liveliness (Ingold, 2011: 133). We can feel the vitality of the landscape in the breezes and raindrops that assail our skin, in the sounds of water and wind, and in the pungent aromas of decay and growth. Yet as I later exemplify, the most evident agent of vitality is the light that pervades the landscape and stimulates our continuous responses to its ever-changing intensities, angles and colours.

A pertinent account about how we see with light and landscape is provided by Alphonso Lingis. Lingis identifies how changing levels of light, characterized by depth of field and brightness, continuously play across space, forming a fluid realm within which we see things and with which we continuously adjust (1998). For instance, when we leave the house at midday in summer we might squint in the strong light spreading across a landscape but we gradually become attuned to the brightness. The luminosity subsequently conditions how we see, as varying inflections of tone, shade and intensity lure our gaze towards particular colours and luminous patches, objects that continually diverge as with shifting patterns of light and shade engender continuous (re)attunement.

Lingis uses the example of a red rose in a hospital room to display its chromatic relationality, as it intensifies the whites of the sheets and greens of leaves, attracting our gaze. Similarly, Gernot Böhme discusses how the shadow of a blue cup does not simply spread darkness across space but also spreads blueness. Böhme (1993: 121) terms the propensity for objects to tincture each other in this way 'ecstatic'. The ways in which a thing casts its colour on surrounding surfaces and other objects, or becomes subsumed within a field of shade, brilliant glare or colour specifies how levels of light continuously produce reconfigured relationships across space. These light effects to which we become attuned, provoke affective and emotional resonances, stimulate movement towards or away from objects, and instigate delight and repulsion. In the landscape, our attention might be attracted by a brightly lit meadow or the dark silhouettes of trees that appear out of an opaque, lucent mist. Consider a hedge that snakes across undulating pasture. Depending on the levels of the light with which we see, this may form a singular black line at twilight, become a 
linear composition of multiple greens in the afternoon glare, or cast a thick, spreading shadow across the fields in the rays of the setting sun.

I also emphasize two further characteristics of seeing with landscape and light. Firstly, vision is entangled with non-visual apprehension, for instance, through a tactile gaze that provokes intimations of texture and temperature without directly sensing them on the skin. Indeed, Catheryn Vasseleau insists that 'tactility is an essential aspect of light's texture... to the feeling of a fabric to the touch, or the grasping of its qualities' (1998: 13). Thus when confronting a landscape, a haptic or tactile vision incessantly emerges, offering the potential for engaging with what we see through sensory imagination and memory (Marks, 2002).

Secondly, as John Wylie (2006) foregrounds, seeing with the light of the landscape involves different modes of looking within shifting fields of varying depth, allowing apprehension of the distinctive planes, angles and densities that differentiate spaces within the landscape. As scenes unfold incessantly and light levels change as we walk through a landscape, we might successively gaze upon vistas, attend to obstacles that lie across the path, glaze over in distraction or contemplation, and scrutinize nearby minutiae. To exemplify our shifting encounters with levels of light in the landscape, Lingis details a brief sojourn in a wood during which he comes across a micro-landscape of lichens to which his gaze continually focuses upon and away from (1998). In this paper, I develop a more extensive approach, identifying multiple variations in the experience of light over a more prolonged spell and along a lengthier, more varied route. I explore how encounters with myriad intensities, levels and depths of daylight coerce my gaze to move across diverse scales of the visible landscape, in the direction of areas of clarity, towards colours, away from bright intensities and into murkiness. This elaborates upon how we respond to the unfolding light conditions of landscape, and continuously re-attune ourselves to changing visual scenes. Such responses to the changing circulation of light between inside and outside can distract vision, strain the eyes, produce optical effects, change mood and alter levels of physical energy.

The stereoscopic human capacity offered by possession of two eyes conveys a sense of the depth of the scenes we encounter and delivers information about the size and position of elements we see. Moreover, the facility to perceive a wide range 
of distinctive colours allow us to discern a multi-hued, variegated landscape. Unlike many birds of prey we cannot see with ultraviolet light nor discern prey from a great distance because of the higher quantity of light receptors in their retina yet our gaze 'does not look at things but roams among them, finding a way through rather than aiming for a fixed target' (Ingold, 2011: 132).

A further distinctive dimension of the human perception of landscape is that it is profoundly shaped by the cultures of looking in which we are situated. As Hannah Macpherson asserts, "neither the sighted nor the visually impaired simply see "what is there"; rather, everybody's seeing involves movement, intention, memory, and imagination' (1049: 2009). The cultural values and understandings through which we make sense of what we see with light veer from the cosmological to the moral, and from the aesthetic to the political, and vary enormously across time and space. The inextricable entanglement of vision with cultural signification underscores that seeing landscape with light does not provide unmediated access to the world. The 'cultural' and the 'natural', and phenomenology and meaning are thoroughly intertwined (Galson, 2013).

This emphasizes that as with all the senses, vision is 'cumulative and accomplished, rather than given' (Stewart, 1999: 18). As Constance Classen emphasises, '(W)e not only think about our senses, we think through them' (1993: 9). One example of this is the propensity for inhabitants of particular landscapes to repeatedly discuss light as a subject in everyday conversation, as exemplified by the prevalence of discussions about weather amongst the British, with common phrases such as, 'it's bright and breezy today' or 'a bit gloomy isn't it?'. Integral to the experience of specific landscapes, light is ingrained in habitual sensations, discourses and practices. It affords distinction and orientation to the time of the day, shapes the seasonal work of gardeners, and informs the modulation of the temperature inside homes.

To emphasise, besides seeing and interpreting landscape with light because of its material qualities and our visual capacities, we also make sense of landscape through the particular cultural conventions (van Dyke 2013) that inform how we look at and understand what we see. For Mitch Rose, cultural interpretations of landscape are fuelled by the imperative to transform 'the vagaries and ramblings of meaning, attachment, and desire circulating in the landscape into sense - that is, into 
something that can be envisioned, set before our mind's eye, or imagined in a mental tableau' (2006: 537). Vision is thus the basis for envisioning, for articulation and representation: the play of light provokes onlookers into making sense of landscape. This resonates with Veronica Strang's insistence that we make meaning with the materiality of the world, through formulating imaginative and symbolic concepts and categories that are aligned with our phenomenological experiences of the landscape (2005). For instance, particular elements within landscapes such as deep forests, inaccessible mountains, raging waterfalls, subterranean caves, perilous swamps, fathomless lakes, expansive deserts and wild seas have served as dominions for supernatural events and mythical creatures. Similarly, various effects of light have accrued numerous symbolic and mythical meanings, with a notable tendency to signify the power of godly or supernatural agency. In ancient religions, the sun served as a ubiquitous divinity and rainbows and lightning seemed to infer evidence of inhuman forces (Weightman,1996).

Such mythical, moral and religious interpretations add to the profusion of symbolic meanings associated with light, underlining the imbrication of the representational and the non-representational in apprehending landscape. This entanglement is profoundly evident in the practices of artists and photographers who endeavour to capture sunsets amongst a wealth of light effects. This artistic engagement with the vital qualities of light and landscape is especially exemplified by the impressionist painters of the $19^{\text {th }}$ century. According to the contemporary poet, Jules Laforgue (cited in Clark, 1984: 16), unlike the discrete colours rendered by the 'academic painter', the impressionist, irrespective of the location, sees light as 'bathing everything not in dead whiteness, but in a thousand conflicting vibrations, in rich prismatic decompositions of colour'. For instance, Georges Seurat's pointillist compositions featured clustered stipples that articulate his concept of chromoluminarism, through which he aimed to capture the affective charge and vibrations of light and colour. The ever-changing light that tints lily ponds, woods, haystack, train stations and cathedrals in Claude Monet's work similarly emphasize the impressionists' preoccupation with capturing light. Indeed, Monet claimed that 'landscape does not exist in its own right, since its appearance changes at every moment; but the surrounding atmosphere brings it to life, the air and the light, which vary continually' (cited in Thornes, 2008: 575). These vital qualities diverge from 
detached attempts to objectively and accurately 'capture' the light of a particular landscape; instead, in their affective and sensual engagement and an emphasis on the temporal dimensions of perception, light is represented as shifting and vibrant.

In a British context, the vitality of the light and landscape is epitomised by the work of JMW Turner, with his vibrant renderings of luminosity and the evanescent vitality of air and light, and by John Constable. Constable undertook a sustained attempt to portray the varying play of light across the ever-changing skies of Salisbury, Suffolk, Hampshire and Hampstead Heath, with the latter the location for more than 100 paintings created at different times of day and season. In foregrounding the work of Constable in his deliberation about the importance of the sky to English landscape and national identity, Pyrs Gruffudd cites the author of a 1946 book on weather who proudly proclaims, 'it is this country with its changing skies and flying cloud shadows that has produced Wordsworth, Constable and Turner' (1991: 19).

Yet the distinctiveness of the British landscape also resonates through everyday apprehension and popular representation, as textures, surfaces, folds and gradients interact with sunlight in characteristic ways. According to Greenlaw (2006), British landscapes generally take shape under cloudiness, mild shadows and weak sunlight that produce a distinctive tonal atmospheres typified by subtle and ever-changing patterns of light and shadow. Yet within the UK, there are profound regional variations in how light conditions the experience of landscape. For instance, in North West Scotland, the play of light seems to be particularly distinctive. Plentiful lochs and fiords shimmer and reflect light, complementing multi-hued, layered mountain vistas, silhouetted pine stands, silvery lochans, vibrant purple heather, glaring mossy greens, brown-green kelp, and the blues and greys of the sea. The North Atlantic Drift generates dramatically changeable clouds of manifold form and shade, and occasionally, extraordinary juxtapositions of patches of deep grey cloud murk and intense outbursts of translucent sunlight that brilliantly animate areas of land.

Very strong associations of light are also embedded in Swedish, Norwegian, Finnish and Danish notions of belonging to place and landscape. Henry Plummer evocatively points to the 'low slant of the sun... long shadows and strikingly refracted colours' that pervade the winter months (2012: 6). During long twilights he describes how 'sky and snow are equally tinged with rainbow hues that linger for hours', and how on 
midsummer evenings 'the sun dissolves into an unreal haze that bathes the land in a fairy-like glow, its colours strangely muted and blurred'. While Plummer acknowledges that there are diverse topographies and ecologies within Nordic landscapes, he submits that 'their skies share a subdued light that imbues the entire region with mystery'(2012: 6-7). As he asserts, these light effects have 'permeated the arts' in these countries, stimulating representations of 'the frailest, most evanescent aspects of nature' (ibid.) and have influenced ecclesiastical architecture (Bille and Sørensen, 2016). These Northern landscapes stand in contrast to those of other latitudes and the often ideologically driven cultural representations that their light inspires: the fierce interplay of shadow and glare that characterizes equatorial landscapes, the relentless and revealing brightness that delineates the countours of Greece (Galton, 2013), and the harsh Australian sunlight that symbolically serves to differentiate the nation from the British colonizing power (Miles, 2013).

Besides contributing to cultural constructions of national belonging, the distinctive effects of light and landscape entice tourists to witness particular phenomenon, and capture them photographically. For instance, consider the growing popularity of trips to experience the 'midnight sun' in the arctic city of Tromsø, the vast crowds that flocked to Cornwall to witness a total solar eclipse on 11 August, 1999, and the lure of the annual 'Fire Fall' in February as the setting sun illuminates the Horsetail Fall in Yosemite National Park, California. These infrequent temporal events exemplify how celestial light can especially enchant particular realms, whereas more subtle and shifting light effects impact on regular encounters with landscape. These light-fuelled encounters attract visitors to particularly esteemed rural landscapes, as in the case of the Peak District National Park, and they resonate in professional and amateur representations in paint, photography and literature.

These examples display that while the light from the sun may possess a similar intensity and rhythm across broad areas of the globe, local variations in weather and above all, the distinctive earthly elements that reflect, refract and absorb light in particular ways shape the ways in which we perceive a landscape. In attempting to capture these changing effects of light in a particular landscape, I have taken a sequence of 50 photographs that chart the sequence of a walk, undertaken in early October, 2015 (these will later be accessible online). The walk, roughly two miles in length, was performed on Stanton Moor, an area of gritstone upland that rises from 
280 to 320 metres above sea level. Situated on the Eastern edge of the Peak District National Park, the moor is characterized by a diverse ecology that includes areas of mixed woodland and heath, and contains disused quarries, erratics and numerous Bronze Age relics. The path followed offered extensive views of the Wye and Derwent valleys, as well as entering substantial areas of dense shrub and wooded stretches.

Photographs are, of course, images that record and are shaped by the qualities of light that is available at a given time and location, as well as the qualities of the camera and the chosen settings that capture light in particular ways. The pragmatic strategy deployed here aimed to regularly photographically record the phases of the route and the diverse qualities of light and shade that conditioned the experience, and thus offers one of the numerous ways in which photographs may be utilized as visual research methods (Rose, 2014). Being attuned to record light in this way meant that I was particularly aware of the changing luminosities and effects of sunlight that emerged over the course of the walk, an attentiveness that would not usually characterize the experience of light and landscape, which would generally be unreflexive (ibid.). Though they only capture moments and suggest a stillness that is not part of a walking experience, the photographs provide intimations of the changing qualities of light, and the affects, sensations and symbolic resonances these may provoke. Primarily however, the photographs primarily acted as a mnemonic device to remind me of the key episodes of the excursion. Accordingly, the following ten short vignettes, accompanied by the photographs that illustrate them, recall those moments when the play of light seemed especially engrossing.

\section{A Walk around Stanton Moor}

\section{A line made by walking and by light}

I step out of the car, eyes squinting at pastoral colours that appear incandescent after the muted palette of Manchester. Vibrant greens, blues and browns produce a more intense radiance that seems to signify the transition from urban to rural. These contrasts in luminosity are also conditioned by the presence of urban air pollution 
that diffuses the sun's rays, and the properties of urban materialities to refract, reflect and absorb light differently. These impressions of a greater radiance are entangled with the cultural meanings imputed to rural landscapes in evocations of the sublime inspired by the play of light manifest in glowering clouds, bursts of sunlight, effervescent sunsets and sunrises, and shimmering mist. Such symbolic resonances inevitably inflect my sensory experience. A stile marks the start of the walk and beyond it, across a field, the path is easily discerned since it is coloured a deeper green than the surrounding grass. Its raised, linear form has been beaten flat by walkers, testifying to the vital impact of humans on landscape and light. The enticing wood to which the path leads is of much darker tone

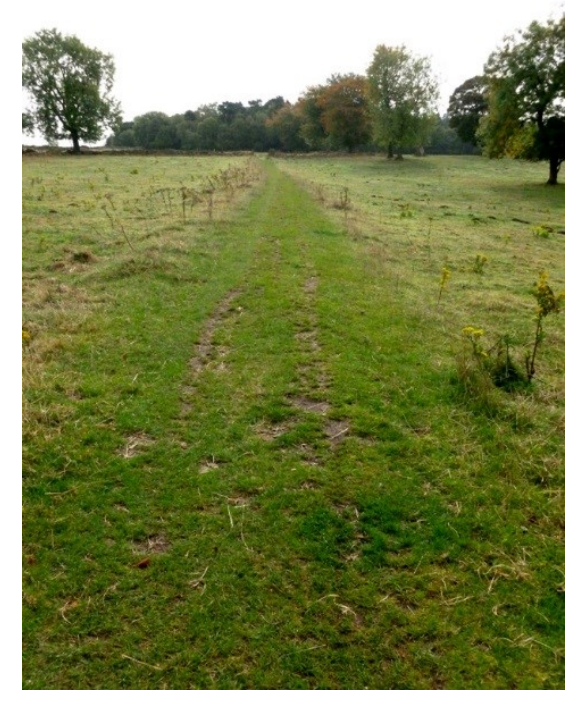

\section{Dappled woodland}

The sparse trees at the wood's entrance create a medley of contrasting shade and brightness, a contrast accentuated by the striking silhouettes of the outlying trees that delineate the border with the sunlit fields beyond. I depart from the path to venture deeper amidst the trees. Their leaves block the sunlight to produce a ceiling of dark green and below, a shady gathering compounded by the grey-green tones of a medieval stone quarry and a dense accumulation of impenetrable undergrowth. So that a path may be forged, vision continuously shifts from leafy floor to middle distance, from the lateral to the close at hand. Subsequently, the levels of light change again as the trees thin out so that sunlight dapples the woodland interior. In 
this kaleidoscopic arboreal realm, rays occasionally burst through the canopy to dazzle the eyes. My attention is suddenly attracted to a sapling, its broad leaves brilliantly illumined by a powerful shaft of sunlight, in ecstatic contrast to its dark green backdrop.
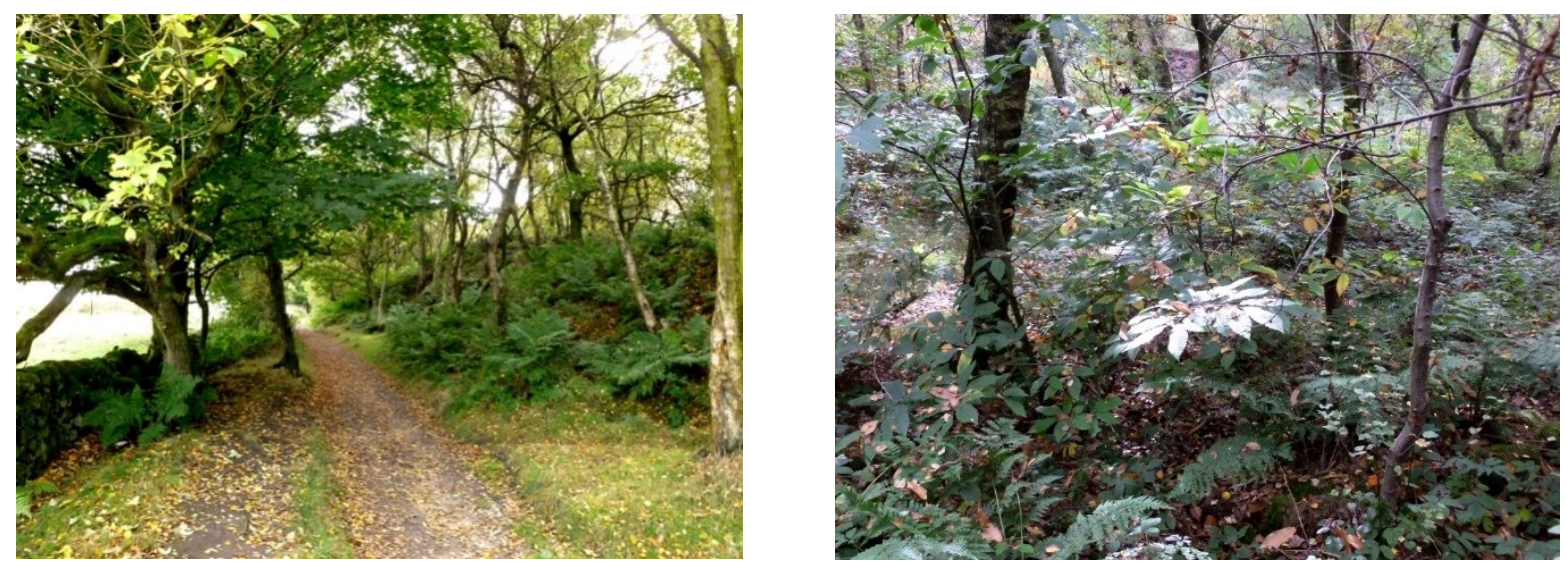

\section{Reflected light}

Out of the wood and back on the path, interspersed shadow and brightness are once more prevalent. A recently upturned tree lies adjacent to the path. Its roots temporarily block out the light, enshrouding my body in shadow and bestowing a sudden chill, demonstrating the capacity for sunlight to bequeath heat as well as vision. Closer inspection discloses that small holes in the crumbling mass of earth, stones and tendrils allow sharp gleams of sunlight to burst through. Further on, the radiance bequeaths a glossy sheen to the fronds of bracken that clothe the open ground. Ahead, the dark forms of fellow walkers stand out conspicuously against the russet and light green tints. A large puddle spreads across the verdant grass, thick with squishy mud. In its still surface, a pellucid glow reflects the luminous sky and the silhouetted trees that rise above. A few feet ahead lie a cluster of silver birch trees, their white bark lucidly reflecting the afternoon sun that shines from the west. These successive levels of light necessitate continuous shifts in my gaze and affective attunement 

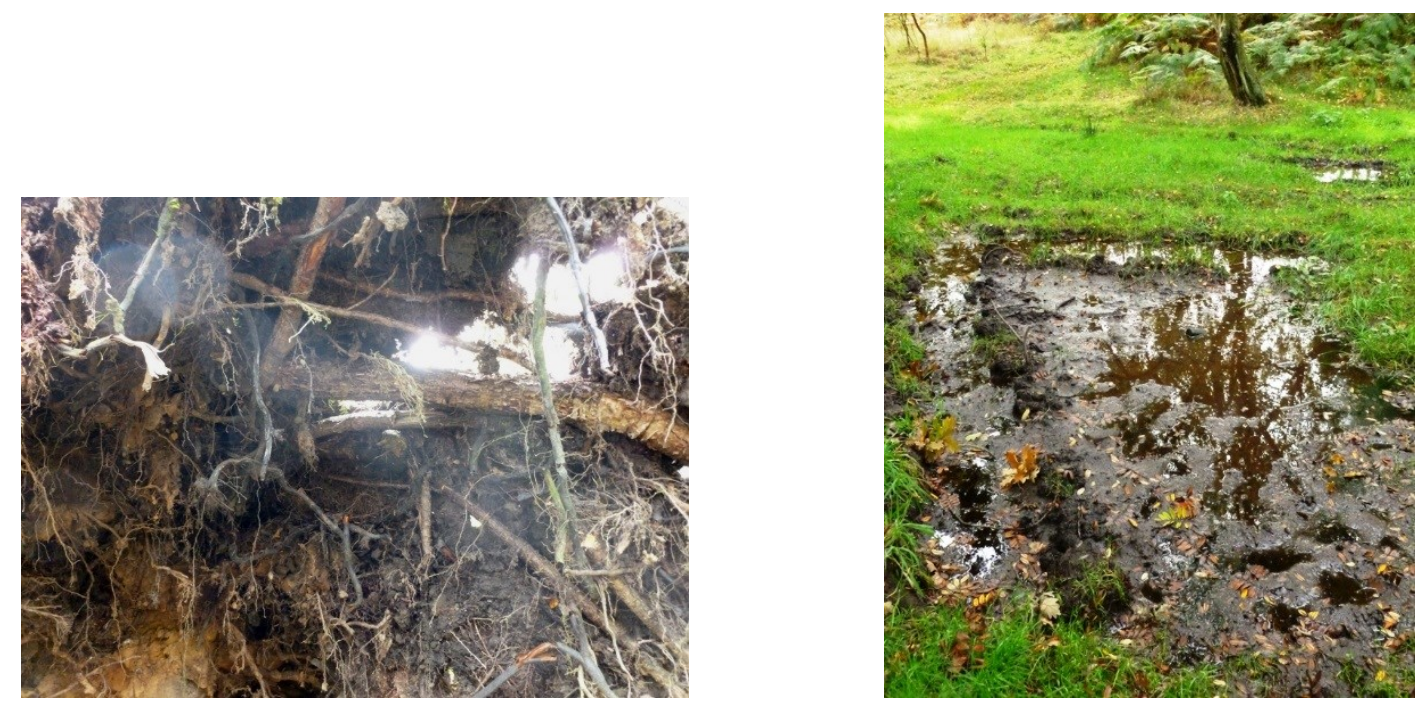

\section{Engineered for light}

The path leads through the patchy woodland into a sheltered glade that encloses Nine Ladies Stone Circle, ten shapely monoliths standing on smooth grass. One of numerous Bronze Age sites that exploit the elevated position of the Moor, a plethora of speculative explanations have endeavoured to puncture the mystery of this enigmatic assembly. Today, New Age pilgrims commemorate the Winter and Summer solstices, reinscribing the mooted relationship of the stones to celestial events, a sacred connection that some contend was honoured in ancient ceremonies. Ribbons and sparkly ornaments adorn adjacent trees, glittering in the sun and accentuating the mythic resonance of this place. Though its purpose and meaning remains inscrutable, it does not take a leap of the imagination to consider that the potency of the site does indeed depend upon the play of shadow and light across the millstone grit stones and the wider landscape. The exposed location seems to connect earth and sky, so that the stones stand out against the land, especially when the sun is at its zenith, or when it casts shadows after dawn and before twilight. The centrality of light to meaning and function seems evident at other ancient sites: archaeologists surmise that Stonehenge served as a celestial observatory at which to celebrate the solstices; and at the Neolithic chambered cairn at Maeshowe, Orkney, the rays of the setting sun shine directly down the entrance passage during the winter solstice. It seems that meaning and practice was shaped 
by the engineering of light, and the phenomenological experience of the materiality and light of such landscapes continues to provoke symbolic interpretation.

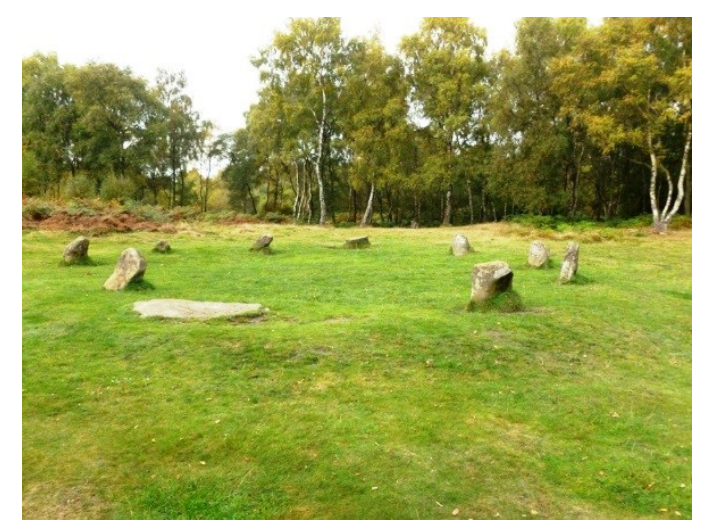

\section{Shimmering gossamer}

After Nine Ladies, the path leaves the woodland behind and enters open moorland, where the bronze and creamy colours of grass and bracken are punctuated by black tangles of dead gorse. Adjacent to the path and spreading out across a cluster of living gorse are myriad cobwebs, a resplendent blanket that would not be apparent if the sun was not shining. Adorned with tiny water droplets, these bejeweled skeins captivate the gaze. This revelation of the collective exertions of thousands of spiders, a tiny fraction of the myriad life-forms that work away in vegetation and soil, discloses that the landscape is colonised by innumerable creatures from the mammalian to the microbial; it is saturated with vitality.

The limitations of our sensorium means that humans can perceive few of these emergent processes: many are too slow for us to recognize although we may acknowledge the outcomes that eventuate, and bacterial and micro-chemical interactions in air and water, inside living things and underground are imperceptible. As John Daniel notes, 'the real action' takes place in 'the vast sectors of the unseen' (2008: 28), including 'the prodigious traffic of food and fluids' and 'the manifold borings and chewings and excretings of countless hidden insects'. Light plays an integral part in this unseen vitality, triggering chlorophyll and causing plants to absorb carbon dioxide and exhale oxygen. 

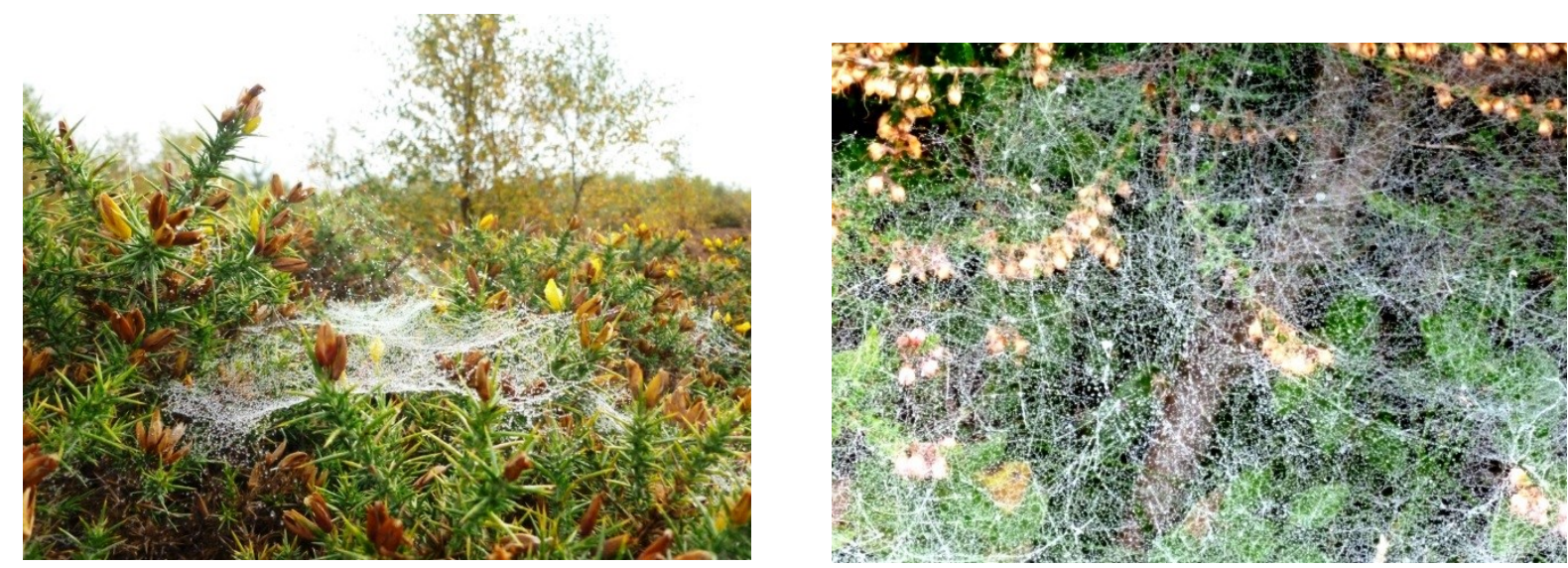

The big sky

The path now opens out more and the gaze shifts to expansive views of the distant fells and valleys, and above all, becomes dominated by the luminescence of the sky. A change in the scale of light's effects across space has extended the perception of the landscape's depth. The most profound evidence of the landscape's vitality is the 'sky-in-formation', characterized by the ever-changing play of light (Ingold, 2011), especially at times when clouds scud across the sky, producing vibrant fluctuations between brightness and shade and altering the tones of the land. The light of the sky fluctuates seasonally, and over the course of the day transitions from the golden hour of dawn to the blue hour of twilight. Yet despite the often overwhelming presence of the sky's radiance, conceptions of landscape have often excluded the celestial, focusing upon that which is of the earth, the landforms, contours and configurations, geomorphologies, natural histories and cultural inscriptions that typify particular kinds of terra firma, perpetuating a spatial 'horizontalism' (Graham and Hewitt, 2013). By contrast, phenomena constituted with light - sunsets, clouds and fog - have been conceived as the immaterial opposite of the material earthliness of the land above which they swirl. Such distinctions between the earthly and the celestial mask how landscape is a fluid and emergent indivisible field. As Tim Ingold (2011: 119) insists, the land is not 'an interface' separating earth and sky but is a 'vaguely defined zone of admixture and intermingling'. Air and water penetrate the earth and photosynthesis absorbs water and carbon dioxide and releases oxygen. To see the sky is to see a light that continuously enfolds and is enfolded into the world. On this day, the sky is composed of changing formations of small grey and 
white fluffy cumulus against a backdrop of whitish-grey, with sparse streaks of blue. This luminosity tints the fading purple of the heather and the swathes of yellow and bleached white grasses. In the middle distance, the verdant green of the valleys stands out against this foreground and the dull yellow of the adjacent hillsides, while further away, the rising High Peak assumes a bluish tone. The occasional stand of trees form prominent silhouettes against the glowing sky while thicker copses, still in leaf, absorb the light to form dark patches.
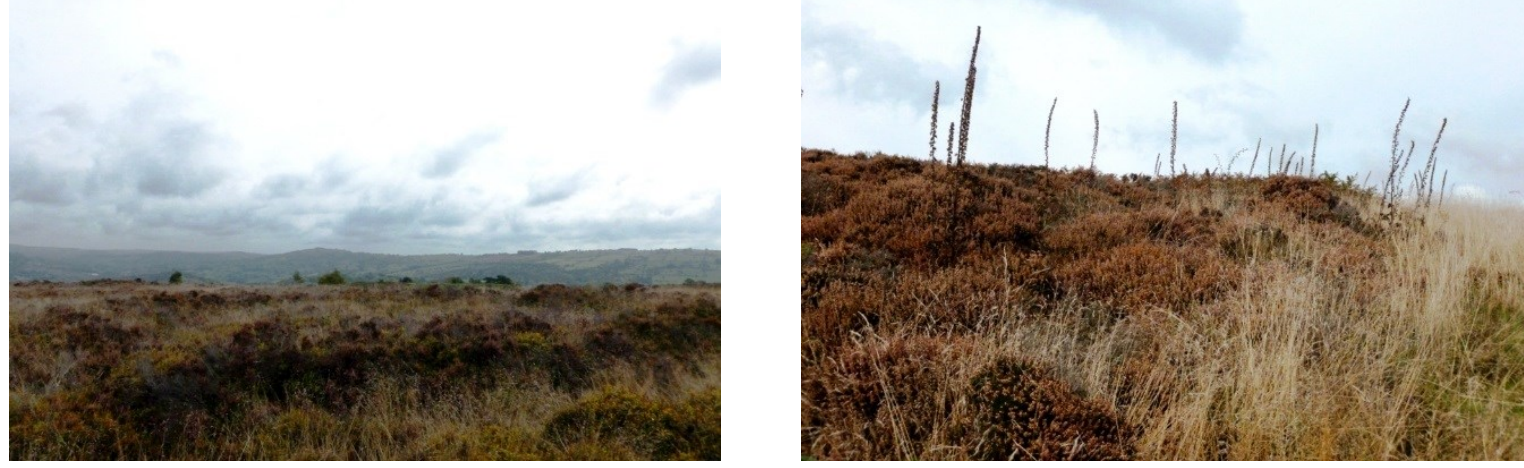

\section{Monolith}

The Cork Stone, sandstone outcrop that has been wrought into an arresting shape by ice, rain and wind, has long been a focus for legends and myths. Its surface is inscribed with graffiti that dates from Victorian times from whence also originate the footholds hewn to facilitate access to climbers who wish to stand atop the stone. I approach the stone with the sun shining upon its ravaged surface, and the light makes prominent these carved features, multiple pockmarks, complex tones and creases, as well as reflecting off fragments of sparkling quartz. This vivid revelation of the stone's surface texture immediately renders the gaze tactile and subsequently invites the hands to run across its grainy, irregular textures. The stone's historical ravages are thus illumined by the sun, soliciting strange affective connections to the past, but moving past the monolith and viewing it with the sun behind, it assumes an entirely different form that provokes a different affective charge, now becoming a looming, hulking silhouette, its mass and weight evoked in its dark bulk, an altogether more mysterious entity precisely because the light does not reveal its intricacies. 

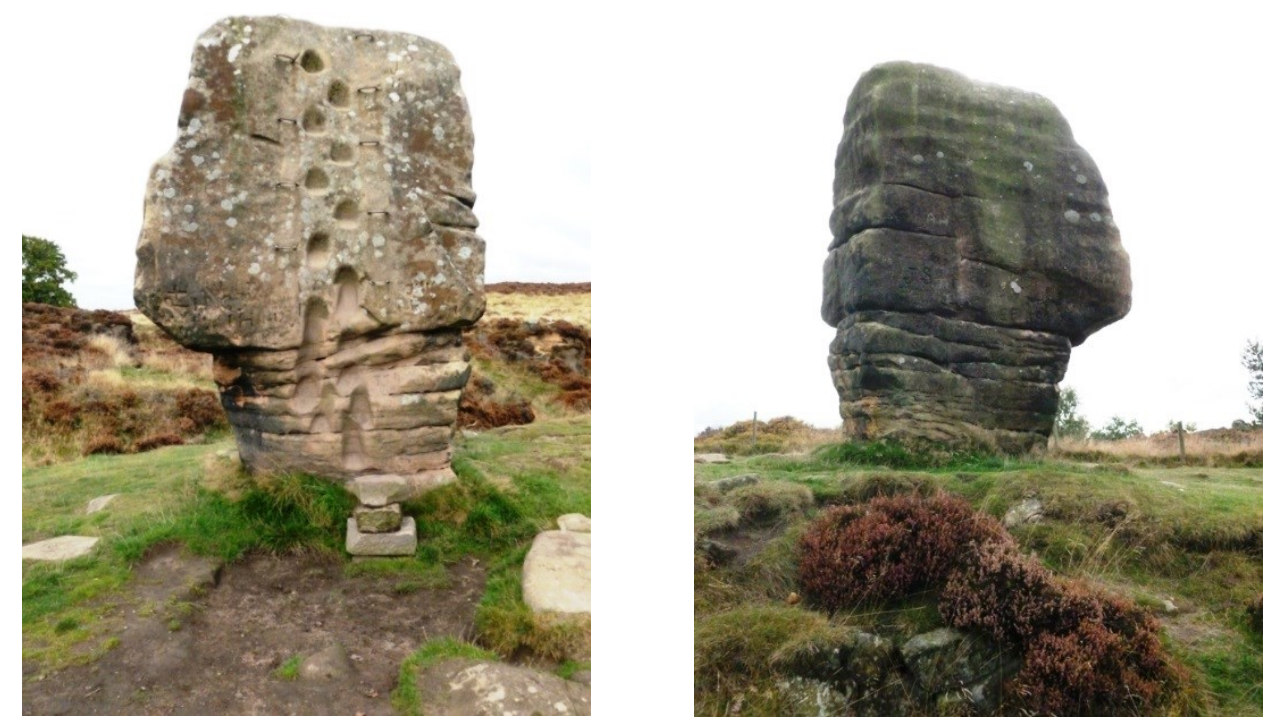

\section{Streaks and depths}

A lengthy stretch of the path through the moor culminates in re-entry into woodland, and it is immediately noticeable that the shadows of the trees are more prominent than those witnessed earlier. This is due to the increased strength of the sun's rays and the more acute angle at which the light hits the land. Now, rather than a dappled effect, the sun conjures a striped pattern across the woodland floor, offering a bolder distinction between light and shade. These streaky repetitions of shadow and sunlight impede progress, making distance and surface more difficult to ascertain, an effect compounded by the optical disruption caused by glare as sunbeams periodically startle the eyes. This difficulty in seeing what is there underpins the deceptive propensities of light, as with the illusory effects that produce a fata morgana or mirages of bodies of water in the middle distance. When we look at the landscape, we cannot be sure that what we see is illusory or not, and may become aware of the limits of our visual capacities.

In these woods, scattered clusters of grey boulders and smaller rocks are embedded in the undulating earth, ornamented with green biofilms and fringed with pale grasses. Within these piles of disaggregated debris, in the spaces between the rocks, small and large holes appear, resonating with a deep blackness. Places where light cannot infiltrate conjure up the secret and the subterranean, or are suggestive of the domains of furtive creatures, once more linking that which light 
discloses or fails to disclose with the symbolic and cultural realm. Here, an enduring and potent darkness lurks beneath that which is visible, and will reign during the night, creating an other-worldly landscape in which scanty light makes perception difficult and shadowy forms summon up unknowable forms (Edensor, 2013). As the accounts of Edwards and Jaramillo explore in this issue, the Peak landscape is riddled with shafts, tunnels and pits, often of unknown depth. Such realms underline how landscape is never solely a matter of what lies on the surface, but is characterized by a complex, multi-dimensional, folded topography.
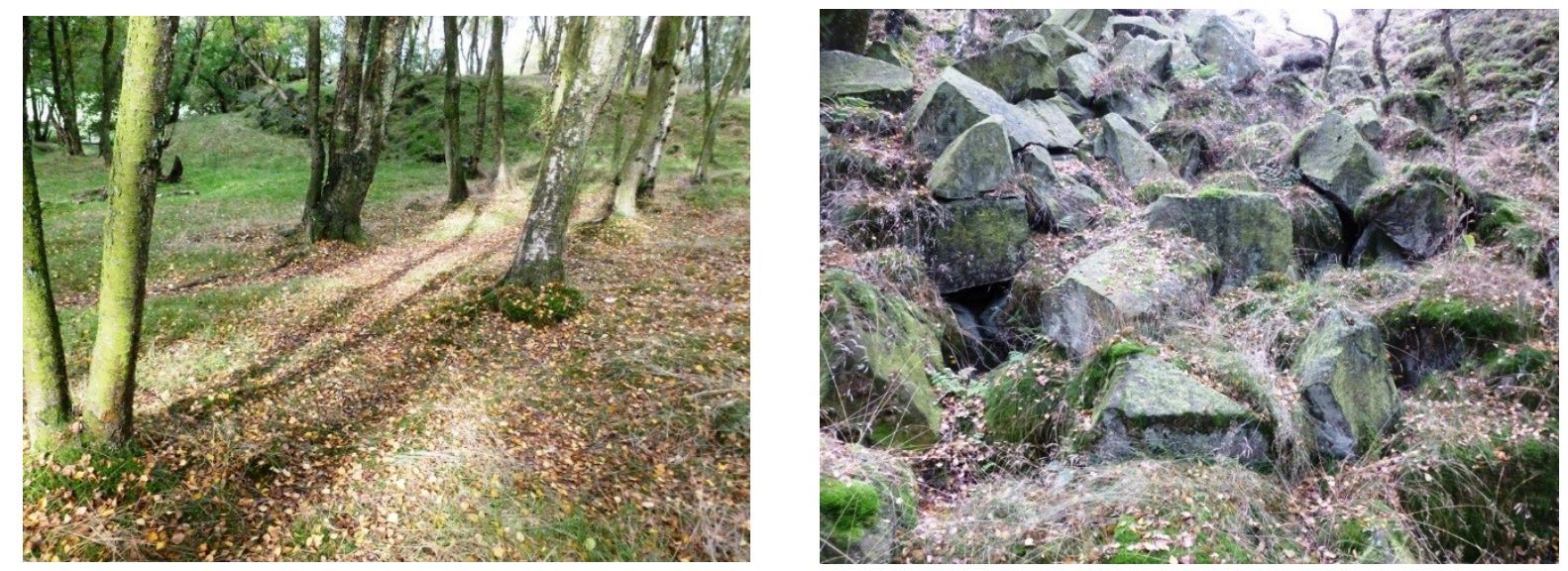

High vis jacket

Esteemed rural landscapes, such as those located in national parks, are often shaped by an intensive management that emphasizes that they are worthy of conservation. This spatial regulation includes the maintenance of architectural and agricultural styles, preservation of valued environments and aesthetic features, and the removal of elements that disturb a prescriptive understanding of what belongs. The monitoring of 'matter out of place' (Cresswell, 1996) is subject to greater scrutiny in national parks than in less valued rural landscapes. However, because of the usual efficacy of these regulatory procedures, a jolting surprise may eventuate when particular unwanted objects have not been removed from cherished scenes. In the midst of sparse woodland, a high vis jacket hangs from the trunk of a silver birch tree. Its fluorescent, highly reflective design has been specifically devised to signify presence and minimize risk to those wearing it by amplifying visibility against any background. Here, it ecstatically dominates the landscape. Although it is an unremarkable, commonplace artifact in the city, such an object is not usually 
encountered in a rural setting. Here, its lurid, reflective tones affectively and aesthetically interfere with the subtler colours of sky, wood and grass, but also solicit speculation about what it is doing here. Who wore this jacket and why? Immediately after this shock of luminescent colour I come across an equally ecstatic spectacle, but one that by contrast, does not seem out of place: a couple of fly-agaric mushrooms, their lustrous, white-speckled red caps radiating against the muted woodland floor.
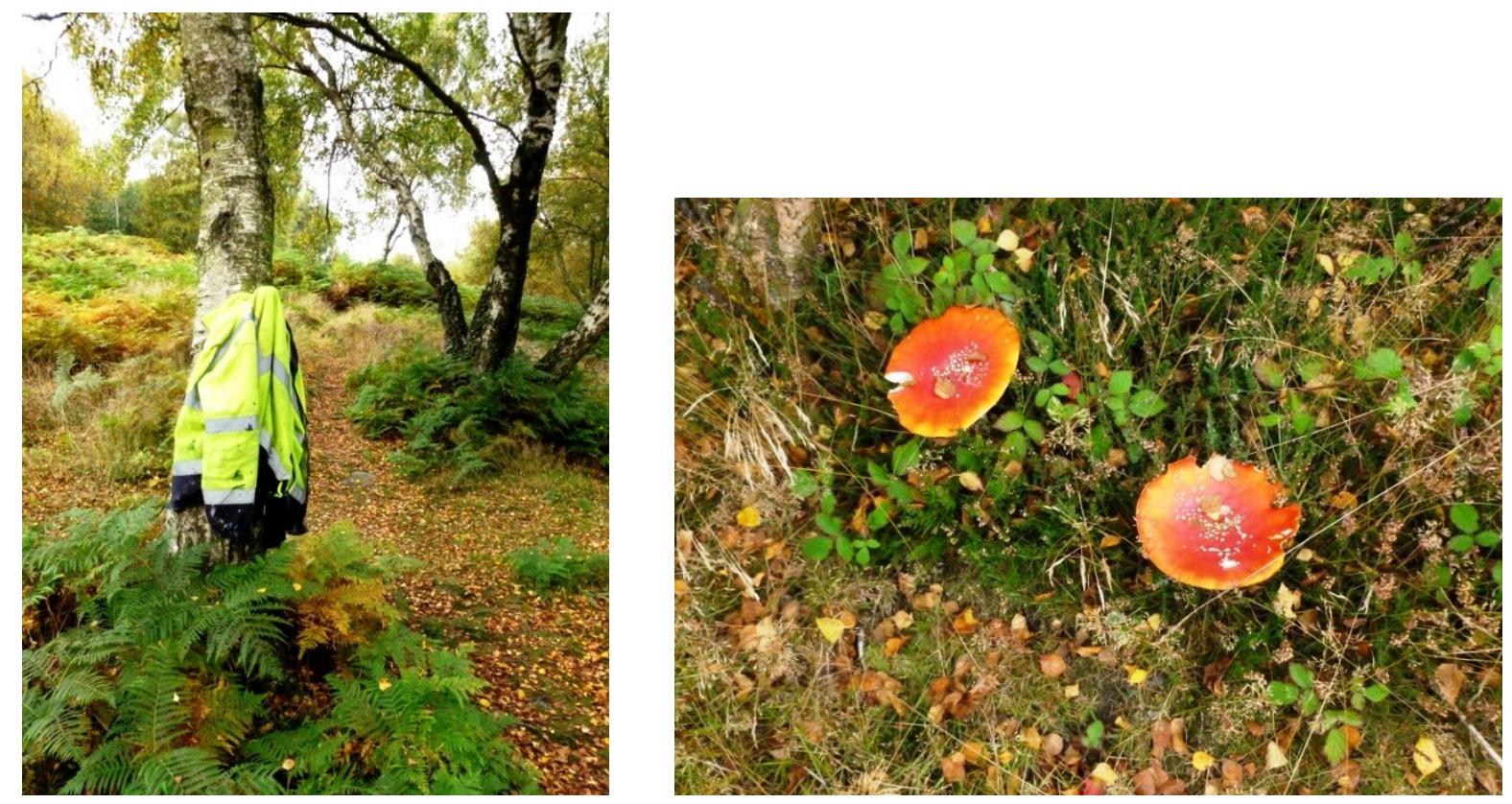

Me and my shadow

Nearing the end of the walk, I am walking along a clear path with an effulgent sun behind me. I suddenly become aware of my own shadow as it stretches out in front of me. Though the shadow is the focus of countless myths, associated with sinister forces, subversive plots, supernatural powers and melodramatic cinema, here it supplements and confirms my own presence in the landscape. The shadow is also a phenomenon that distorts the human form and engenders illusion. My shadow does not accurately represent my shape and dimensions but stretches or shortens my figure, accentuating the appendages and limbs but concealing all other features. Nevertheless, it affirms that my body impacts upon the landscape through which I move. I cannot be an abstracted, dispassionate entity who views and evaluates; rather, I am a body that even for a short time, is part of this landscape, one of the 
infinite elements that interacts with the circulating vitality of light, air and matter. I block out the light and make a moving shadow on the earth.

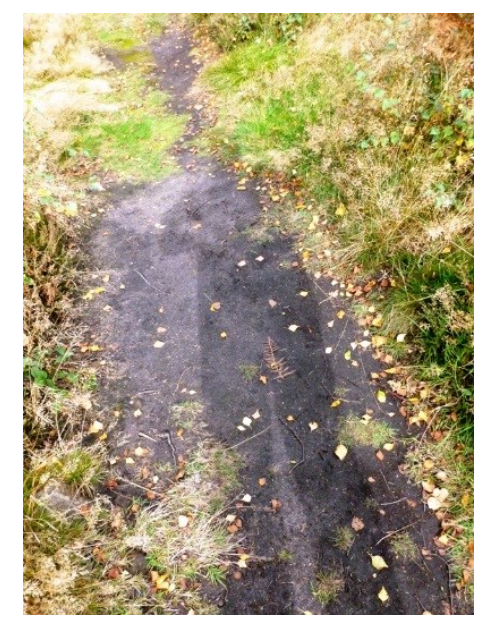

\section{Conclusion}

This paper has endeavoured to address a significant lacuna in theories of landscape: the key role of light in perception, sensation and meaning. The vital element of light circulates between our visual apparatus and the landscape that we see, refuting any notion that we are somehow detached observers who can objectively discern enduring qualities, points underlined by our specifically human ways of apprehending colour, depth and detail. Engagement with its changing qualities involves continuous attunement to landscape, as we move and mingle through the flux and phases of light, a process I have illustrated in an account of a walk through the distinctive Peak District landscape of Stanton Moor. The moments and passages through which the effects of light on the landscape seemed particularly potent is rendered textually and photographically to foreground the mainfold ways in which light successively solicits particular sensory, perceptual, affective, epistemological and imaginative engagements. During the walk, a range of experiences are foregrounded: the ecstatic shimmer and glow of light as it radiates upon particular features in the landscape, its capacity to reveal that which is often unseen or unnoticed, its inability to penetrate certain spaces thus producing shadows and areas of darkness saturated with imaginary potency, its potential to solicit more-than-visual sensory intimations, an awareness of the human uses of light from the prehistoric to contemporary reflective garments, light's critical agency in the landscape's vitality, 
and its tendency to confuse and mislead visual perception. I have also demonstrated the changing scales of apprehension as light encourages the gaze to repeatedly move from the close at hand, to the path ahead, and to distant hills, the sky and the horizon. Throughout, I have emphasised the thorough entanglement of phenomenological and symbolic responses to the experience of light in the landscape, privileging neither.

I have also demonstrated that particular landscapes can be characterized by the light that falls on them. While it is true that similar climatic, atmospheric conditions extend across spaces of similar latitude - here for instance, over Northern Britain and through Northern Europe - what is crucial is that light is reflected, refracted and absorbed in distinctive ways by the organic elements and materialities that the landscape possesses. The affordances of characteristic geologies, vegetation, quantity of tree cover, building forms, bodies of water, undulations and gradients are inflected by changing levels of light in particular ways.

The light of the Peak District is also shaped by its rural location, in contradistinction to the large urban conurbations of South Yorkshire, Greater Manchester, Stoke-onTrent and the East Midlands that spread close to its borders. The national park is conceived as an oasis of clarity away from these surrounding cities, its air clearer and skies less murky. This notion seems to be confirmed by the assignation of three dark sky points in the park, situated in places that escape the polluting effects of skyglow that limit opportunities to see the stars. This is a landscape that thus contrasts with the bright lights of the surrounding urban landscapes and appears very different in the dark (Edensor, 2013), but also, these less polluted conditions also offer a more pellucid and variable radiance.

Bender, B. (2001) 'Introduction', in B. Bender and M. Winer (eds) Contested Landscapes: Movement, Exile and Place, Oxford: Berg

Benedicktsen, K. and Lund, K. (2010) 'Introduction: starting a conversation with landscape' in K .Benedicktsen and K. Lund (eds) Conversations with Landscape, Farnham, Ashgate 
Bille, M. and Sørensen, T. (2016) 'In visible presence: the role of light in shaping religious atmospheres', in K. Papadopoulos and G. Earl (eds) Oxford Handbook of Light in Archaeology, Oxford: Oxford University Press.

Böhme, G. (1993) 'Atmosphere as the fundamental concept of a new aesthetics'. Thesis Eleven, 36(1): 113-126

Clark, T.J. (1984) The Painting of Modern Life: Paris in the Art of Manet and his Followers, Princeton: Princeton University Press

Classen, C. (1993) Worlds of Sense: Exploring the Senses in History and Across Cultures, London: Routledge

Cosgrove, D. (1984) Social Formation and Symbolic Landscapes, London: Croom Helm.

Cresswell, T. (1996) In Place / Out of Place: Geography, Ideology and Transgression, Minneapolis, MN: University of Minnesota Press

Daniels, S. (1993) Fields of Vision: Landscape Imagery and National Identity in England and the United States, Cambridge: Polity Press.

Edensor, T. (2013) 'Reconnecting with Darkness: experiencing landscapes and sites of gloom', Social and Cultural Geography, 14(4): 446-465

Edensor, T. (2011) 'Entangled agencies, material networks and repair in a building assemblage: the mutable stone of St Anns Church, Manchester', Transactions of the Institute of British Geographers 36(2): 238-252

Galson, S. (2013) The "singular light": phenomenology in its landscape', Cultural History, 2(2): 247-261

Graham, S. and Hewitt, L. (2013) 'Getting off the ground: on the politics of urban verticality', Progress in Human Geography, 37(1): 72-92

Greenlaw, L. (2006) Between the Ears: 'The Darkest Place in England', BBC Radio $3,(25 / 3 / 06)$

Gruffud, P. (1991) 'Reach for the sky: the air and English cultural nationalism', Landscape Research, 16(2): 19-24 
Ingold, T. (2011) Being Alive: Essays on Movement, Knowledge and Description, London: Routledge

Lingis, A. (1998) Foreign Bodies, Bloomington, In: Indiana University Press

MacPherson, H. (2009) 'Theintercorporeal emergence of landscape: negotiating sight, blindness, and ideas of landscape in the British countryside', Environment and Planning A, 41: 1042-1054

Marks, L. (2002) Touch: Sensuous Theory and Multisensory Media, Minneapolis, MN: University of Minnesota Press

Miles, M. (2013) 'Light, nation, and place in Australian photography', Photography and Culture, 6(3): 259-277

Mitchell, W. (ed.) (1994) Landscape and Power, London: University of Chicago.

Morris, N. (2011) 'Night walking: darkness and sensory perception in a night-time landscape installation', Cultural Geographies, 18(3): 315 -342

Plummer, H. (2012) Nordic Light: Modern Scandinavian Architecture, London: Thames and Hudson

Rose, G. (2014) 'On the relation between "visual research methods" and contemporary visual culture', Sociological Review, 62(1): 24-46.

Rose, M. (2006) 'Gathering "dreams of presence": a project for the cultural landscape', in Environment and Planning D: Society and Space, 24: 519-535

Rose, M. and Wylie, J. (2006) 'Animating landscape', Environment and Planning D: Society and Space, 24: 475-479

Saito, Y. (2008) 'Appreciating nature on its own terms', in A. Carlson and S. Lintott (eds) Nature, Aesthetics and Environmentalism: From Beauty To Duty, New York: Columbia.

Stewart, S. (1999) 'Prologue: from the museum of touch', in J. Aynsley, C. Breward and M. Kwint (eds), Material Memories: Designs and Evocation, Oxford: Berg. 
Strang, V. ( 2005) 'Common senses: water, sensory experience and the generation of meaning', Journal of Material Culture, 10(1): 92-120

Thornes, J. (2008) 'Cultural climatology and the representation of sky, atmosphere, weather and climate in selected art works of Constable, Monet and Eliasson', Geoforum, 39(2): 570-580

Van Dyke, C. (2013) 'Plastic eternities and the mosaic of landscape', Environment and Planning D: Society and Space 2013, volume 31, pages $400-415$

Vasseleau, C. (1998). Textures of Light: Vision and Touch in Irigaray, Levinas and Merleau-Ponty, New York: Routledge.

Weightman, B. (1996) 'Sacred landscapes and the phenomenon of light', Geographical Review, 86(1): 59-71

Wylie, J. (2006) 'Depths and folds: on landscape and the gazing subject', in Environment and Planning D: Society and Space, 24: 537-554

Wylie, J. (2007) Landscape, London: Routledge

\section{Acknowledgements}

Big thanks to Mikkel Bille and Julian Holloway for comments on this paper as well as the anonymous referees and the journal editor. Also enormous appreciation for Uma Kothari in accompanying me on this journey. 